\title{
BRICKLAYING R0BOT LIFTING AND LEVELLING SYSTEM
}

Piotr Wos*, Ryszard Dindorf, Jakub Takosoglu

Department of Manufacturing Engineering and Metrology,Faculty of Mechatronics and Mechanical Engineering, Kielce University of Technology, Kielce, Poland

*E-mail of corresponding author: wos@tu.kielce.pl

\section{Resume}

The article presents the concept of building and controlling a Bricklaying Robotic System (BRS). The research presents the design process and how to control a four-cylinder electro-hydraulic servo drive system. The article presents a mathematical model and optimizes the process of aligning the mobile support platform of the masonry robot. The lifting mechanism was presented and its kinematic analysis performed. The mathematical model of the hydraulic system was described. The control system, designed for the masonry robot lifting platform, includes position errors for a single drive axis and synchronization errors between the axes.

\section{Article info}

Received 17 September 2020

Accepted 26 January 2021

Online 23 June 2021

\section{Keywords:}

bricklaying robot, electro-hydraulic servo drive, levelling system

\section{Introduction}

The construction services market is a dynamically changing market in Europe, with a high indicator of sensitivity to economicfluctuations.The main limitations and problems associated with the traditional way of performing masonry work are: the low availability of qualified masonry brigades, timeliness and loyalty of executive resources towards the service recipient, maintaining constant accuracy and repeatability of masonry works and thus satisfactory, work pace related to efficiency, human work not supported by robotic tools. These factors cause difficulties with maintaining the schedule of works performed in accordance with the planned standard, which in the case of many investments, results in imposing financial penalties on the general contractor. The concept of a robotic masonry system for the construction services market brings a fundamental change in the specifics of the masonry services market through unique and innovative features of the system's functionality: fast masonry works in 24-hour operation - increasing the capacity of building recipients of technology, automating masonry - reducing the need for cheap employees, reducing the risk of losing contractors, reducing the cost of services, improving safety - fewer injuries and accidents, improving the accuracy of construction works and their repeatability.

Masonry works are one of the very early human craftsmanship. However, this discipline has not achieved a high degree of automation. A number of attempts were made to develop mobile construction works, the most advanced of which were the projects [1-2]. These studies date back to the early 90 s of the 20 th century, when the motivation for designers was to improve the efficiency and savings of building construction, mainly through the use of ability of machines to carry larger loads. These works, although very advanced, did not find full practical application because they were not flexible enough to adapt and respond to various situations occurring on the construction site. Thanks to introduction of digital technologies in architecture, research centers such as Harvard GSD, Carnegie Mellon and the University of Stuttgart have created research laboratories [3]. These centers have developed various technologies and prototype elements aimed at increasing the role of robots in construction works, in particular bricklaying. In addition, some commercial masonry works were developed, such as Hadrian and Semi Automated bricklaying robot SAM, which perform masonry processes. The common feature of these projects is that they have all tried to replace building materials with new materials that may be more suitable for the use of robots [4].

Contemporary works, intended for construction works, can be divided into several categories: remote controlled robots, which are controlled by a human using a remote control, where decisions are made by the operator based on the collected information, programmable construction machines in which the operator can choose from a function menu or teach a robot 


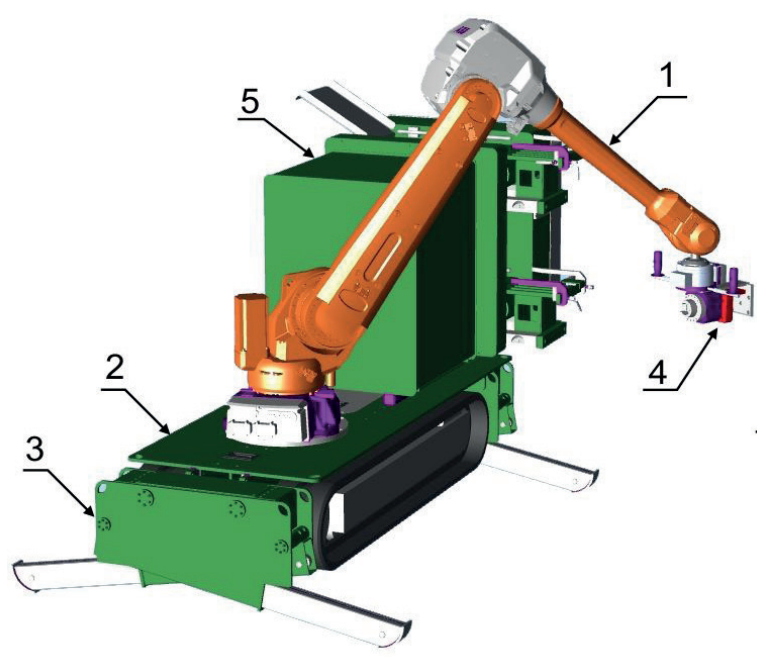

Figure1 Model view Bricklaying Robotic System (BRS) 1 - basic robot (BR)with 6 DoF, 2 - mobile hydraulic module (MHM) 3 - support modules (SM), 4 - gripper, 5 - bricks feeder

to perform a new function, intelligent systems in which unmanned, fully automated construction machines perform tasks without direct human intervention. This category may also include the semi-automatic machines that are not completely unmanned and some level of human control is present.

Since the bricklaying is a repetitive process, it can easily be automated. To carry out the masonry process, the robot must detect and then take a brick from the warehouse. Then, the brick should be placed in the right position on a properly prepared base - mortar. During the capturing and laying bricks, the robot should avoid collisions with obstacles. For such a dynamic area as a construction site, obstacles detection requires the active motion planning techniques based on the realtime sensory data. In addition, the bricklaying machine must be "aware" of the progress of wall evolution. To introduce this technology during the masonry work, the following basic technical problems must be solved: robot movement along the erected wall, accurate reference of the robot working area axis relative to the entire wall (building), creating and programming complex interactions within the working area for the process collecting and laying of individual bricks, creating and programming interactions for the process of filling joints with mortar [5].

As a part of the research and development works, a design of the Bricklaying Robotic System (BRS) prototype was made (Figure 1), meeting the expectations of construction companies in the field of robotization of time-consuming and arduous manual construction works.

The Bricklaying Robotic System (BRS) consists of a basic robot (BR) (1) equipped with a gripper (4). Basic robot (BR) is placed on a Mobile Hydraulic Module (MHM) (2). The BRS is equipped with a lifting and positioning control system, as well as a control system

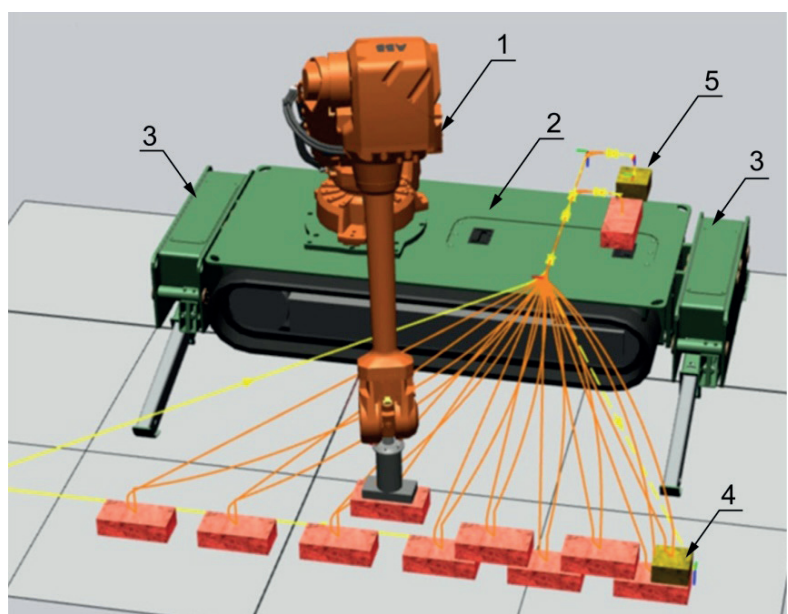

Figure 2 Simulation tests of the bricklaying process: 1 basic robot (BR) with $6 \mathrm{DoF}$,

2 - mobile hydraulic module (MHM) 3 - support modules (SM), 4 -.masonry wall, 5 - brick warehouse item

for working movements of the basic robot. Concept of control system for levelling, as well as the system of indicators for measuring and controlling BRS work parameters, were developed. The BRS will have a feeder with a reservoir (5) for various building materials used during bricklaying, and a mortar feeder. Figure 2 shows the process of bricklaying simulation of the designed BRS prototype.

The designed BRS creates a wall $3.1 \mathrm{~m}$ high and $5.08 \mathrm{~m}$ long from one parking position.

\section{Dynamic model of the MHM}

Figure 3 shows the model of the Mobile Hydraulic Module (MHM). The Mobile Hydraulic Module is a support platform for further development of devices used in cooperating construction works, such as: construction manipulator, material warehouse or lifting platform. It is composed of a mobile platform, which ensures the movement of MHM and the two supporting modules (SM). Each of the supporting modules has extendable legs with a cross structure, which are lowered by means of two electro-hydraulic servo drives [6]. The main task of the platform is to move the BRS to the designated working area and then precisely raise the BRS to the desired height along with its levelling. Both of these tasks are significantly influenced by the dynamic behaviour of the mobile module itself and the mechanisms mounted on it.

Calculation diagram of the single supporting module (SM) consisting of the double-acting cylinder with onesided piston rod and proportional directional control valve is presented in the Figure 4 [7]. The mass of the load $\mathrm{M}$ was placed centrally on a plane $2 \mathrm{a}$ wide and $2 \mathrm{~b}$ long for simplicity.

For the module (MHM) (Figure 3) the following 


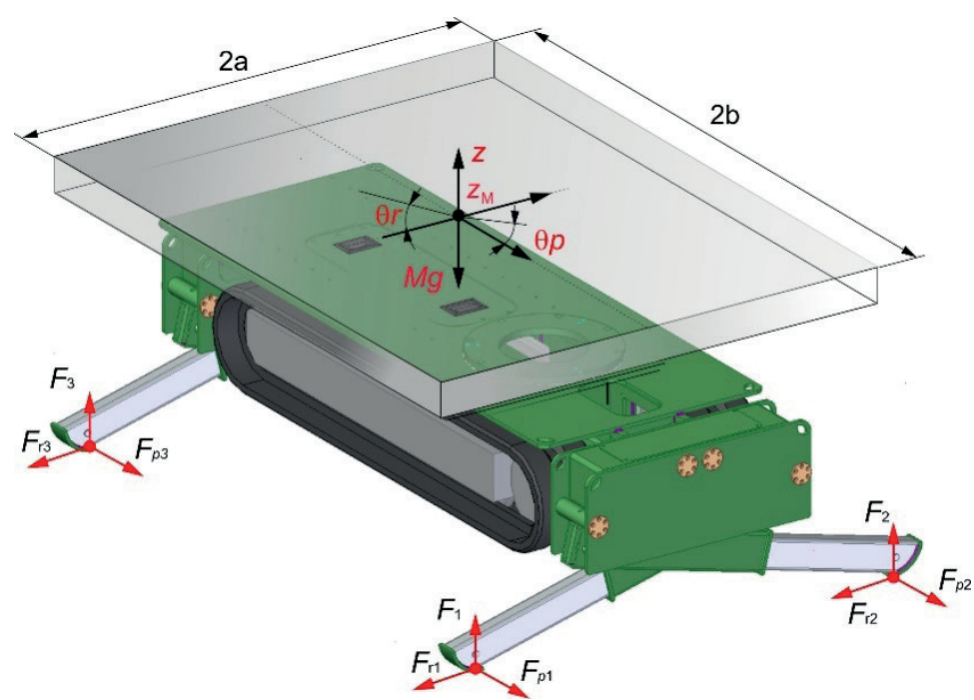

Figure 3 Mobile Hydraulic Module (MHM)
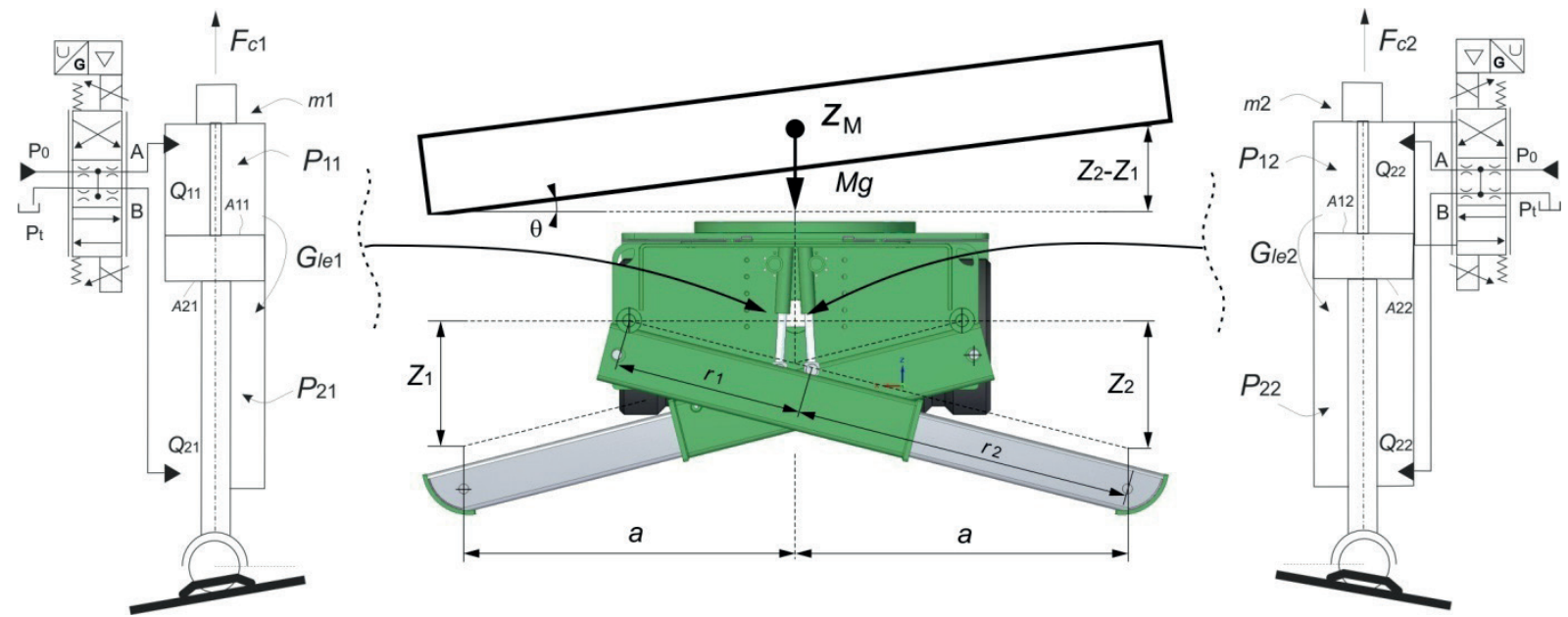

Figure 4 Scheme of the support modules (SM) and the hydraulic cylinders: $Q_{1 i}$ - volumetric flow rate, $C_{1 i}, C_{2 i}$ - fluid capacitances in the cylinder chambers, $G_{l e i}$ - coefficients of leakages in the cylinder, $A_{1 i}, A_{2 i}$ - effective areas of cylinder's piston, $p_{1 i}, p_{2 i}$ - pressure in individual cylinder's chambers, $F_{c i}$ - reaction forces for electrohydraulic servo drives, $m_{i}-$ the mass of the pistons, $r_{1}, r_{2}$ - mounting dimensions of the hydraulic cylinder and the support (legs), $p_{0}$ - supply pressure, $p_{T}$ - pressure in the tank

equations of motion along the direction of gravity and rotation around the axis $X$ ( $r$ - roll) and $Y$ ( $p$ - pitch) can be obtained:

$$
\begin{aligned}
M \ddot{z}_{M} & =\sum_{i=1}^{4} F_{i}+\sum_{i=1}^{4} F_{r i} \sin \left(\theta_{r}\right)+\sum_{i=1}^{4} F_{p i} \sin \left(\theta_{p}\right)-M g \\
J_{r} \ddot{\theta}_{r} & =\sum_{i=1}^{4}\left(\left(F_{i}+F_{r i} \sin \left(\theta_{r}\right)\right) a_{r i}\right. \\
J_{p} \ddot{\theta}_{p} & =\sum_{i=1}^{4}\left(\left(F_{i}+F_{p i} \sin \left(\theta_{p}\right)\right) b_{p i}\right.
\end{aligned},
$$

where: $z_{M^{-}}$the coordinate determining the vertical position of the geometrical center of the platform, $M$ total mass of the load, $g$ - gravitional constant, $F_{i}, F_{r i}$, $F_{p i}$ - reaction forces for -mechanical supports (legs) for $i=1,2, \ldots 4, n=4, a_{r i}, b_{p i}$ - arms' lengths for moments of forces, $J_{r}, J_{p}$ - moments of inertia, $\theta_{r}, \theta_{p}$ - angles of rotation. If one assumes that $\theta_{r}, \theta_{p}$ are small, then $\sin \left(\theta_{r}\right) \approx 0$ and $\sin \left(\theta_{p}\right) \approx 0$.
Equations containing the mechanical and hydraulic variables for the single support module (SM) are described by (Figure 4):

$$
\begin{aligned}
& F_{i}=A_{1 i} p_{1 i}-A_{2 i} p_{2 i} \\
& Q_{1 i}=A_{1 i} \dot{z}_{i}+C_{1 i} \dot{p}_{1 i}+G_{l e i}\left(p_{1 i}-p_{2 i}\right), i=1,2, \\
& Q_{2 i}=A_{2 i} \dot{z}_{i}-C_{2 i} \dot{p}_{2 i}+G_{l e i}\left(p_{1 i}-p_{2 i}\right)
\end{aligned}
$$

where: $Q_{1 i}$ - volumetric flow rate, $C_{1 i}, C_{2 i}$ fluid capacitances in the cylinder chambers, $G_{l e i}$ - coefficients of leakages in the cylinder, $A_{1 \mathrm{i}}, A_{2 \mathrm{i}}$ effective areas of cylinder's piston, $p_{1 \mathrm{i}}$, $p_{2 \mathrm{i}}$ - pressure in individual cylinder's chambers.

The hydraulic forces developed by the actuators are given by:

$$
\begin{aligned}
& {\left[p_{1 i} \cdot A_{1 i}-p_{2 i} \cdot A_{2 i}\right]=} \\
& {\left[A_{1 i} \cdot p_{0}-A_{2 i} \cdot p_{T}-\frac{A^{3}{ }_{1 i}+A^{3}{ }_{2 i}}{\left(K_{1} \cdot u+K_{0.1}\right)^{2}} \cdot h_{i}{ }^{2}\right], i=1,2,}
\end{aligned}
$$


where: $u_{i}$ - control inputs, $K_{1}, K_{01}$ - constants factors, $p_{0}$ - supply pressure, $p_{T}$ - pressure in the tank, which corresponds to the main and leakage valve flow paths.

The equation of motion of each hydraulic cylinder piston is:

$m_{i} \ddot{z}=\left(P_{1 i}-P_{2 i}\right) A_{2 i}-b_{i} \dot{z}-F_{c i}$

and the equations of motion of the support module (SM) are:

$\left\{\begin{array}{l}F_{1}+F_{2}-M g=M \ddot{z}_{M}, \\ \left(F_{1}+F_{2}\right) a=J \ddot{\theta}\end{array}\right.$,

where: $\quad x_{M}=\left(z_{1}+z_{2}\right) / 2, F_{i}=F_{c i} \frac{r_{1}}{\left(r_{1}+r_{2}\right)}$ and $\theta=\left(z_{1}-z_{2}\right) / 2 a$.

Due to the symmetrical shape of the MHM, it can be assumed that the center of gravity of the platform is in the middle. The system can be described by the formulas:

$$
\left\{\begin{array}{l}
M_{L} \ddot{z}_{g}=L_{m} G-m g \\
G=K_{i}\left(z_{0}-z_{i}\right)+B_{i}\left(\dot{z}_{0}-\dot{z}_{i}\right), i=1,2, \cdots n, n=4, \\
m \ddot{z}_{L}=F-G
\end{array}\right.
$$

where:

$G=\left[G_{1}, G_{2}, \cdots, G_{n}\right]^{T}$, is a vector of loading forces, $z_{q}=\left[z_{1}, z_{2}, \cdots, z_{n}\right]^{T}$, is the platform displacement vector, $z_{h}=\left[z_{h 1}, z_{h 2}, \cdots, z_{h n}\right]^{T}$, is the hydraulic cylinder displacement vector,

$L_{m}=\left[\begin{array}{cccc}1 & 1 & \cdots & 1 \\ a_{r 1} & a_{r 2} & \cdots & a_{r n} \\ b_{p 1} & b_{p 2} & \cdots & b_{p n}\end{array}\right]$, is an arm matrix with a fixed moment relative to the axis $r$ (roll) and $p$ (pitch),

$M=\left[\begin{array}{c}M \\ 0 \\ 0\end{array}\right]$, is a mass load matrix,

$F=M A \cdot\left[\begin{array}{c}A_{11} \cdot p_{11}-A_{21} \cdot p_{21}-m_{1} g \\ A_{12} \cdot p_{12}-A_{22} \cdot p_{22}-m_{1} g \\ A_{13} \cdot p_{13}-A_{23} \cdot p_{23}-m_{1} g \\ \cdots \\ A_{1 n} \cdot p_{1 n}-A_{2 n} \cdot p_{2 n}-m_{n} g\end{array}\right]$, is the matrix

of forces generated by hydraulic cylinders, $M A=\frac{r_{1}}{\left(r_{1}+r_{2}\right)}$ is a mechanical advantage.

$M_{L}=\operatorname{diag}\left(\left[\begin{array}{lll}M & J_{r} & J_{p}\end{array}\right]\right) L_{r p}^{-1}$, is the load inertia matrix, where: $L_{r p}=\left[\begin{array}{ccc}1 & a_{r 1} & b_{p 1} \\ 1 & a_{r 2} & b_{p 2} \\ \vdots & \vdots & \vdots \\ 1 & a_{r n} & b_{p n}\end{array}\right]$

$K_{i}=\operatorname{diag}\left(\left[\begin{array}{llll}k_{1} & k_{2} & \cdots & k_{n}\end{array}\right]\right)$, is the contact stiffness matrix, $\quad B_{i}=\operatorname{diag}\left(\left[\begin{array}{llll}b_{1} & b_{2} & \cdots & b_{n}\end{array}\right]\right)$, is the contact viscous damping coefficient matrix.

\section{$3 \quad$ Lifting process MHM}

The process of extending the support module (SM) takes place in two stages: the extension of the module legs to the maximum elongation, followed by the MHM lifting process. The lifting process can be divided into three stages. The first stage occurs when the crossdrive cylinders quickly extend to the ground without load. After placing the legs on the ground, the second stage occurs, when the support cylinders synchronously extend to a certain height. This is followed by a levelling step when the MHM actuators move according to the horizontal slope relationship to complete the levelling. After thelevelling, the MHM platform is locked mechanically.

\subsection{Synchronous movement}

The problem of synchronization of many linear hydraulic cylinders arises in heavy, hydraulically controlled applications such as lifting devices, construction and agricultural machinery [8-9]. This problem is the most often solved by introducing an additional hydraulic resistance to each parallel actuator branch, adjusted manually or automatically. In the case of manually adjustable hydraulic resistance, this boils down to the use of a throttle valve and in the case of automatically adjustable hydraulic resistance, the use of a flow regulator. In both cases, the idea of solving the problem of motion synchronization boils down to creating additional pressure drops in the power supply branches of individual drives so that the pressure in the pump discharge line, determined from the equilibrium pressure equations arranged for the power branches of individual drives, is the same [10-12].

During the synchronization, the differential position errors between the hydraulic actuators converge to zero. The position error of $i$-th hydraulic actuator is defined as follows:

$e_{i}(z)=z_{i}^{d}(t)-z_{i}(t)$

where $z_{i}^{d}(t)$ is the desired generated length and $z_{i}(t)$ is the actual measured length of $i$-th hydraulic actuator.

The position error vector of four actuators is:

$e(t)=\left[e_{1}(t), e_{2}(t), e_{3}(t), e_{4}(t)\right]^{T}$.

If the ratio of the actual position of each hydraulic actuator at each sampling time is equal to that of all the other actuators, then the MHM moves in a synchronous manner. The synchronization goal is understood to be as follows: 


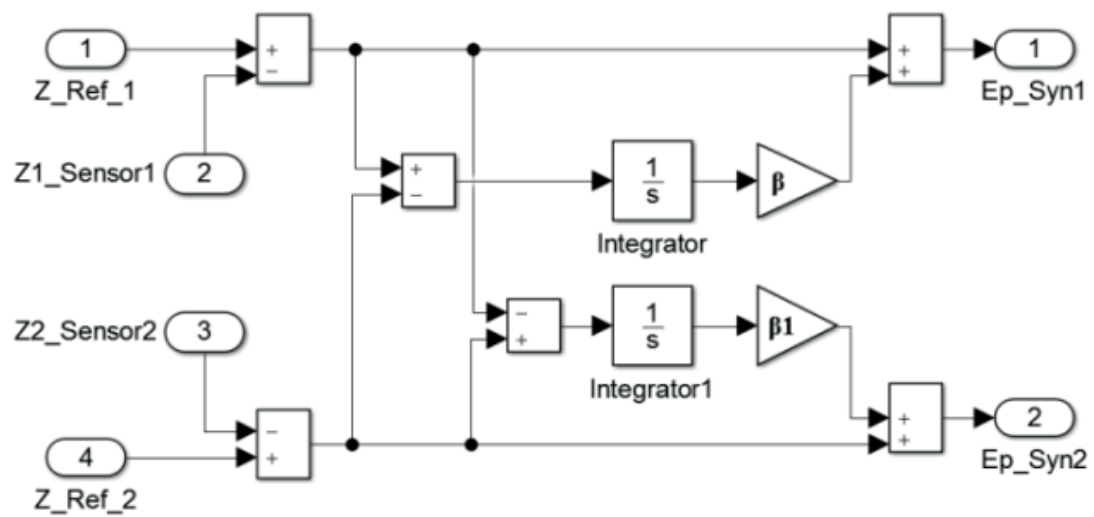

Figure 5 Scheme of a subsystem of the synchronization controller in Matlab/Simulink

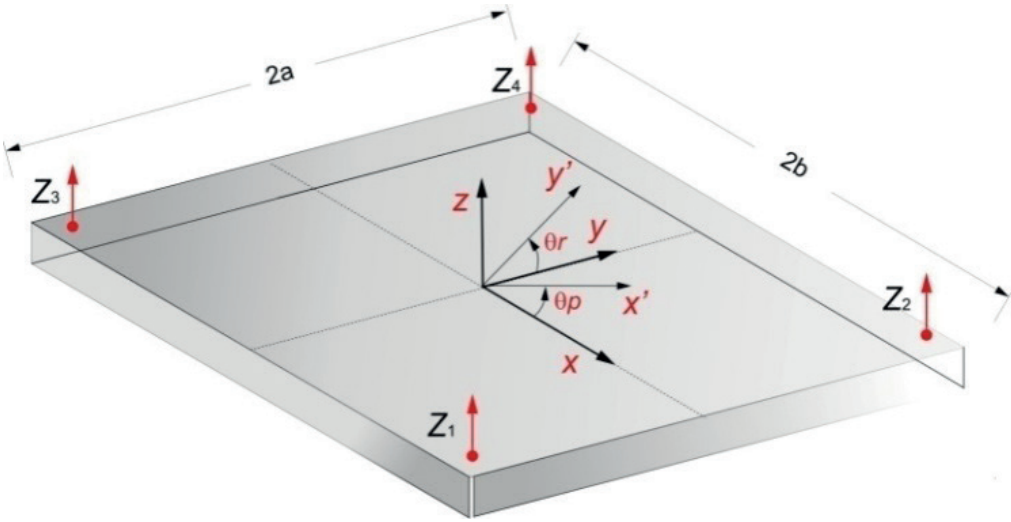

Figure 6 Coordinate system for MHM

$e_{1}(t)=e_{2}(t)=e_{3}(t)=e_{4}(t)$.

Thus, the synchronization error is defined as:

$\left\{\begin{array}{l}\varepsilon_{1}(t)=e_{1}(t)-e_{2}(t) \\ \varepsilon_{2}(t)=e_{2}(t)-e_{3}(t) \\ \varepsilon_{3}(t)=e_{3}(t)-e_{4}(t) \\ \varepsilon_{4}(t)=e_{4}(t)-e_{1}(t)\end{array}\right.$.

The position control system is designed by combining the position error and synchronization error. Herein, in conceiving the cross-coupled controller (CCC), the crosscoupling error $c_{i}$ includes the position error $e_{i}$ and the synchronization error $\varepsilon_{i}$ :

$c_{i}(t)=e_{i}(t)+\beta_{i} \int_{0}^{t} \varepsilon_{i}(\omega) d \omega$

where $\beta_{i}$ is the positive coupling parameter which, determines the weight of the synchronization error, wherein as $\beta_{i}$ increases, the synchronization error $\varepsilon_{i}$ decreases, $\omega$ is a parameter at a variable time, from $t=0$ to $t$.

The position synchronization error looks for the difference between the position errors of many axes and is based on the synchronization function (12).

The block example diagram of the synchronization function designed in Matlab/Simulink is shown in Figure 5 [13].

\subsection{Levelling}

To obtain the relationship between the slope and displacement angles of hydraulic cylinders, it was assumed that the angle $\theta_{p}$ (pitch) is measured from the $X$-axis and the angle $\theta_{r}$ (roll) from the $Y$-axis in the direction of the $Z$ axis. The purpose of levelling is to set the surface of the robot platform so that these angles are zero. The determined coordinate system is shown in Figure 6.

For this coordinate system, one can write the rotation matrices as:

$$
\begin{aligned}
& R_{x}\left(\theta_{r}\right)=\left[\begin{array}{ccc}
1 & 0 & 0 \\
0 & \cos \theta_{r} & \sin \theta_{r} \\
0 & -\sin \theta_{r} & \cos \theta_{r}
\end{array}\right], \\
& R_{y}\left(\theta_{p}\right)=\left[\begin{array}{ccc}
\cos \theta_{p} & 0 & \sin \theta_{p} \\
0 & 1 & 0 \\
-\sin \theta_{p} & 0 & \cos \theta_{p}
\end{array}\right] .
\end{aligned}
$$

In fact, during the leveling process, the deviation in the platform level is small. With this assumption, one can determine the following relationships: $\cos \theta_{r}=\cos \theta_{p}=1$ and $\sin \theta_{r}=\theta_{r}, \sin \theta_{p}=\theta_{p}$

The equation for the coordinate transformation of a levelling plane is obtained as follows:

$$
\left[\begin{array}{l}
x^{\prime} \\
y^{\prime} \\
z^{\prime}
\end{array}\right]=R_{x}\left(\theta_{r}\right) R_{y}\left(\theta_{p}\right)\left[\begin{array}{l}
x \\
y \\
z
\end{array}\right],\left[\begin{array}{l}
x^{\prime} \\
y^{\prime} \\
z^{\prime}
\end{array}\right]=\left[\begin{array}{ccc}
1 & 0 & \theta_{p} \\
0 & 1 & \theta_{r} \\
-\theta_{p} & \theta_{r} & 1
\end{array}\right]\left[\begin{array}{c}
x \\
y \\
z
\end{array}\right] .
$$




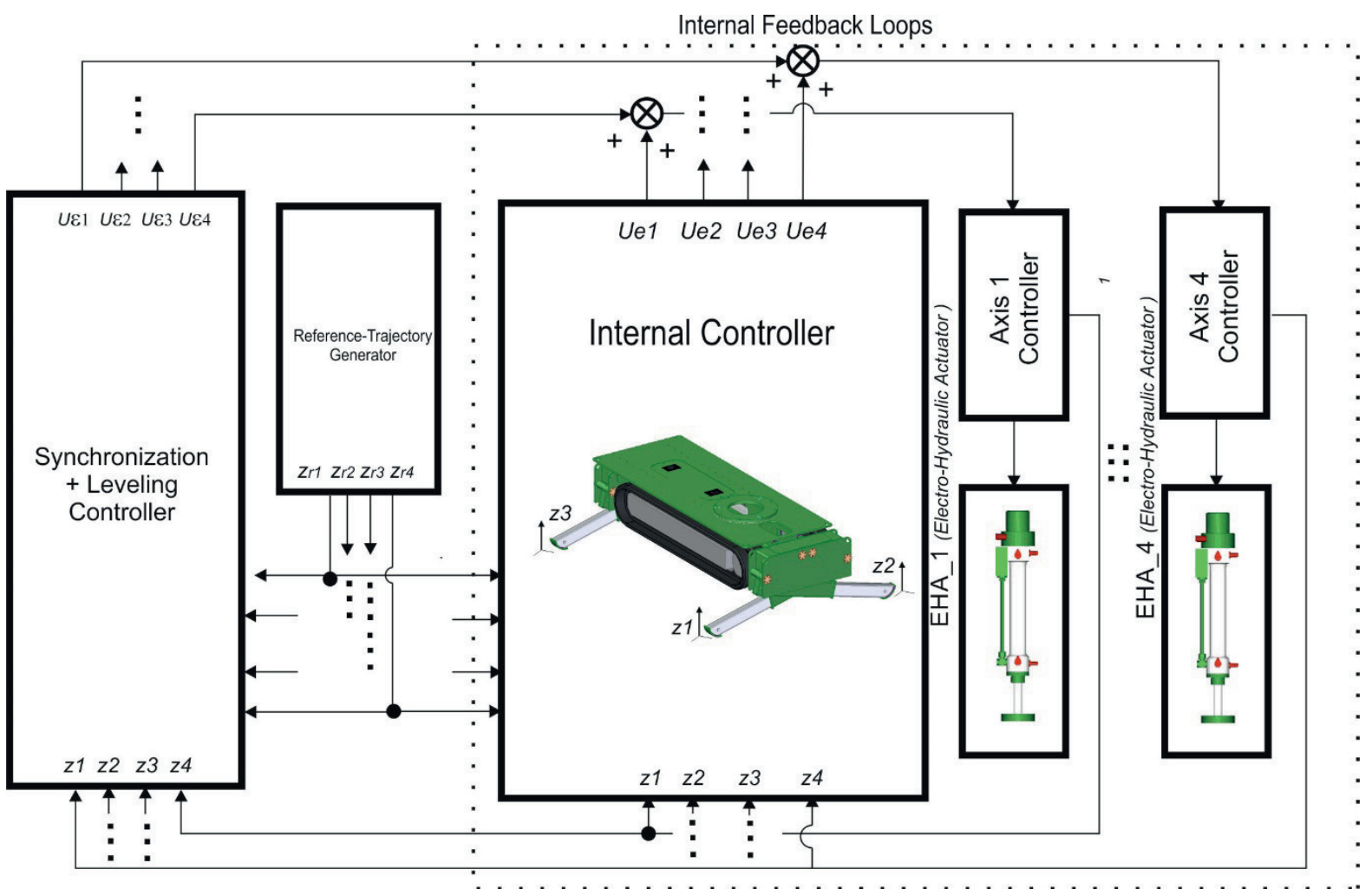

Figure 7 The controller block diagram of the MHM with synchronization
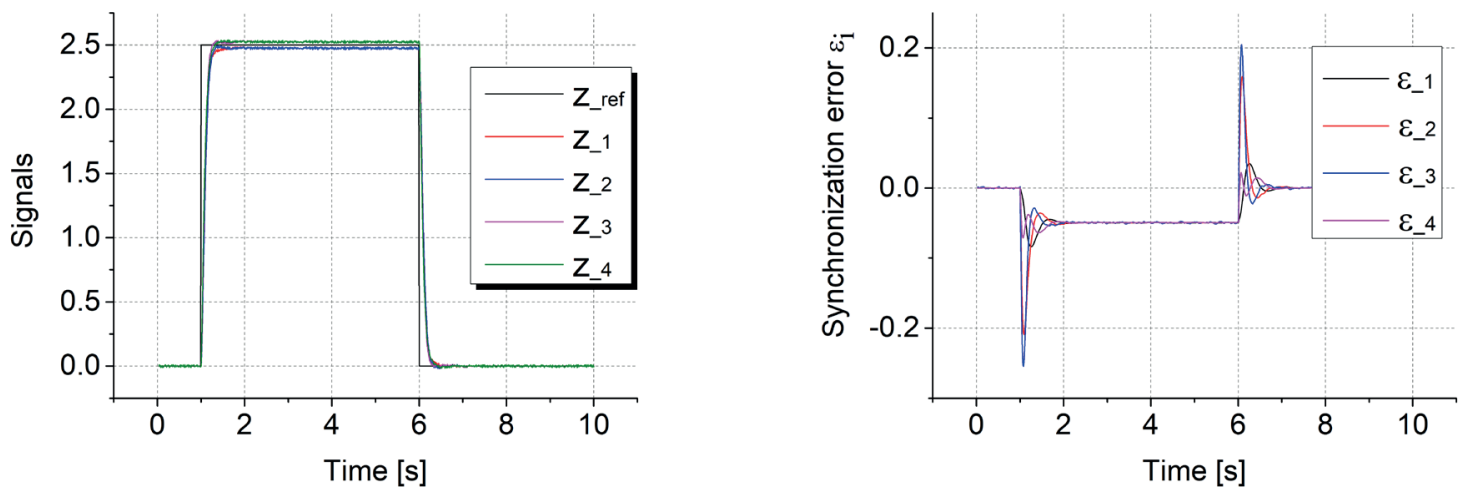

Figure 8 Synchronization error $\varepsilon_{i}$ for references rectangular input signals

Table 1 Simulation parameters

\begin{tabular}{ccccccc}
\hline simulation parameters & $\begin{array}{c}p_{S} \\
(\mathrm{MPa})\end{array}$ & $\begin{array}{c}M \\
(\mathrm{~kg})\end{array}$ & $\begin{array}{c}A_{1 i} \\
\left(\mathrm{~m}^{2}\right)\end{array}$ & $\begin{array}{c}A_{2 i} \\
\left(\mathrm{~m}^{2}\right)\end{array}$ & $\begin{array}{c}2 a \\
(\mathrm{~mm})\end{array}$ & $\begin{array}{c}2 b \\
(\mathrm{~mm})\end{array}$ \\
\hline values & 16 & 1000 & $1.256 \times 10^{-3}$ & $1.134 \times 10^{-3}$ & 1568 & 2358 \\
\hline
\end{tabular}

Each zero value of offsets $z_{1}, z_{2}, z_{3}$ and $z_{4}$ means the highest position in relation to the other legs of the supports.

$$
\left\{\begin{array}{l}
z_{1}=0, z_{2}=2 a \cdot \theta_{r}, z_{3}=-2 b \cdot \theta_{p}, \\
z_{4}=-2 b \cdot \theta_{p}+2 a \cdot \theta_{r}, \\
z_{1}=2 a \cdot \theta_{r}, z_{2}=0 \cdot \theta_{r}, z_{3}=-2 b \cdot \theta_{p}-2 a \cdot \theta_{r}, \\
z_{4}=-2 b \cdot \theta_{p}, \\
z_{1}=2 b \cdot \theta_{p}, z_{2}=2 b \cdot \theta_{p}+2 a \cdot \theta_{r}, z_{3}=0, \\
z_{4}=2 a \cdot \theta_{r}, \\
z_{1}=2 b \cdot \theta_{p}-2 a \cdot \theta_{r}, z_{2}=2 b \cdot \theta_{p}, z_{3}=-2 a \cdot \theta_{r}, \\
z_{4}=0 .
\end{array}\right.
$$

Figure 7 shows the control system diagram for the MHM with synchronization and levelling.

For the simulation purposes constant values of parameters were accepted and implemented (Table 1).

Figure 8 shows the diagrams of synchronization error $\varepsilon_{i}$ for references rectangular input signals.

Figure 9 shows the diagrams of synchronization error $\varepsilon_{i}$ for references sinusoidal input signals.

Graphs of angles $\theta_{r}$ (roll) and $\theta_{p}$ (pitch) are shown in Figure 10. 

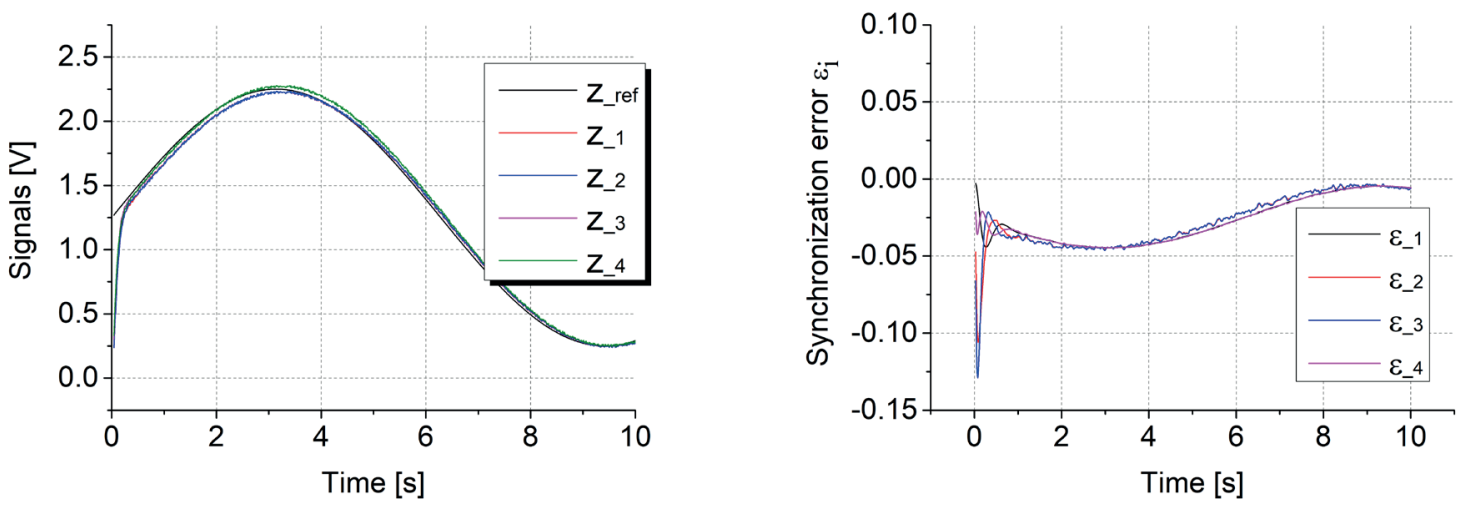

Figure 9 Synchronization error $\varepsilon_{i}$ for references sinusoidal input signals $z_{\text {iref }}=0.08 \mathrm{~Hz}$
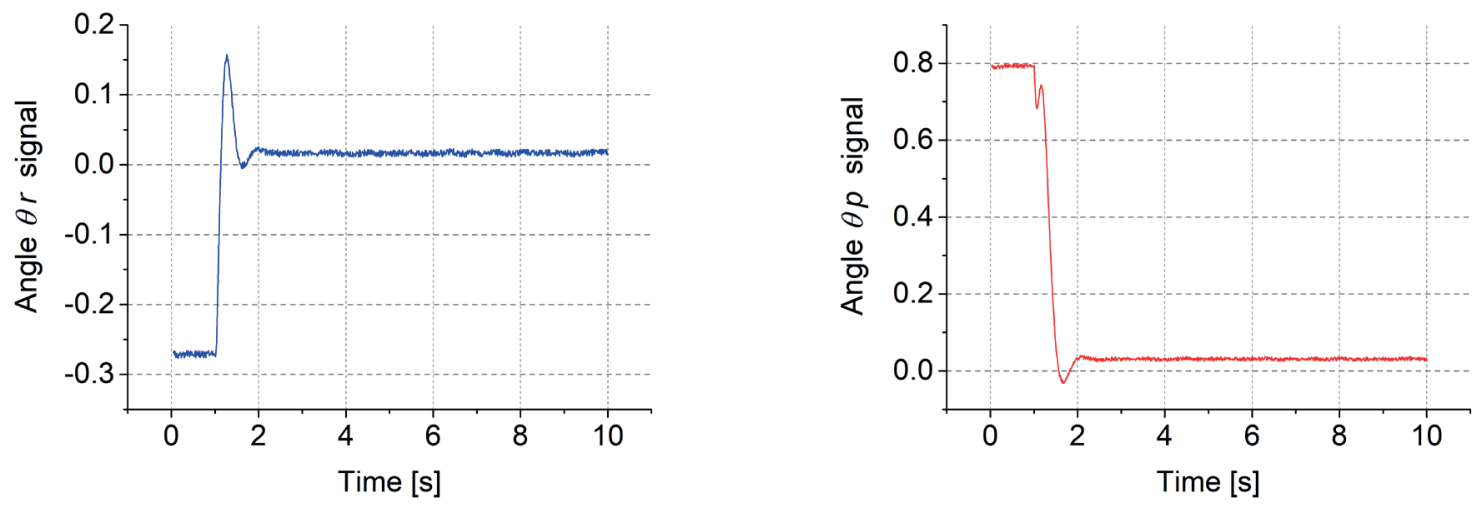

Figure 10 Levelling angle signals: $\theta_{r}$-roll and $\theta_{p}$-pitch

\section{Summary}

A technical solution was presented to the lifting and leveling system of the mobile hydraulic module (MHM) unit, where the electro-hydraulic control and drive systems were used. This assembly is used to displace, position and transport the Bricklaying Robotic System (BRS). A model of platform MHM dynamics was presented along with a model of hydraulic drives. A control system diagram was developed. Simulation tests were carried out to test the accepted scheme of the bricklaying robot. The presented MHM control system uses feedback from platform bracket position errors, synchronization errors and tilt angles.

\section{Acknowledgment}

This research was financially supported by The National Centre for Research and Development in Poland (Grant No. POIR.04.01.02-00-0045/18-00).

\section{References}

[1] AGUAIR, M. L., BEHDINAN, K. Design, prototyping, and programming of a bricklaying robot. Journal of Student Science and Technology [online]. 2015,8(3), p. 27-34. Available from: https://doi.org/10.13034/jsst.v8i3.92

[2] ANDRES, J., BOCK, T., GEBHART, F. First results of the development of the masonry robot system ROCCO. In: 11th International Symposium on Automation and Robotics in Construction ISARC: proceedings [online]. 1994. ISBN 9780444820440, p. 87-93. Available from:https://doi.org/10.1016/B978-0-444-82044-0.50016-3

[2] SPATH, I. D., SCHMIDT, I. J., ANDRES, D. I. J. Robot systems for residential building construction: integration and operation. In: 14th International Symposium on Automation and Robotics in Construction ISARC: proceedings [online]. 1997. p. 185-197. Available from:https://doi.org/10.22260/ISARC1997/0023

[3] HELM, V., ERCAN, S., GRAMAZIO, F., KOHLER, M. Mobile robotic fabrication on construction sites DimRob. In: IEEE/RSJ International Conference on Intelligent Robots and Systems IROS: proceedings [online]. IEEE, 2012. p. 4335-4341.Available from: https://doi.org/10.1109/IROS.2012.6385617 
[5] ARDINY, H., WITWICKI, S., MONDADA, F., Are autonomous mobile robots able to take over construction? International Journal of Robotics. 2015, 4(3), p. 10-21. ISSN 2008-7144.

[6] RADZYMINSKI, B., GOSZCZAK, J. Test stand for modelling hydraulically controlled continuously variable transmission, The Archives of Automotive Engineering - Archiwum Motoryzacji [online]. 2017, 78(4), p. 63-77. eISSN 2084-476X.Available from: http://dx.doi.org/10.14669/AM.VOL78.ART5

[7] WOS, P., DINDORF, R. Nonlinear modeling and parameter identification for electro-hydraulic servo system. In: IEEE'2019 - 20th International Carpathian Control Conference: proceedings [online]. IEEE, 2019. p. 1-5. Available from: https://doi.org/10.1109/CarpathianCC.2019.8765947

[8] NING, S., WANG, S., Synchronization control to the hydraulic width system in hot rolling. In: IEEE2010 International Conference on Measuring Technology and Mechatronics Automation: proceedings. IEEE, 2010. p.710-713.

[9] SUN, D., Position synchronization of multiple motion axes with adaptive coupling control. Automatica [online]. 2003, 39(6), p. 997-1005. ISSN 0005-1098. Available from: https://doi.org/10.1016/S0005-1098(03)00037-2

[10] DZIUBAK, T., SZCZEPANIAK, P. Model of the rate of flow of hydraulic fluid leaking through precision pairs in the electrohydraulic controller of an automatic transmission. The Archives of Automotive Engineering Archiwum Motoryzacji [online]. 2017, 78(4), p. 43-61. eISSN 2084-476X. Available from: https://doi.org/10.14669/ AM.VOL78.ART3

[11] KASSEM, S., EL-DIN, T. S., HELDUSER, S., Motion synchronization enhancement of hydraulic servo cylinders for mould oscillation. International Journal of Fluid Power. 2012, 13(1), p.51-60. ISSN 1439-9776, eISSN 2332-1180.

[12] LIU, Z., GAO, Q., YU, C., LI, X., GUAN, W., DENG, G., Collaborative synchronization digital control for double hydraulic cylinders. Advances in Mechanical Engineering [online]. 2014, 2014(1), p. 1-18. Available from: https://doi.org/10.1155/2014/371403

[13] WOS, P, DINDORF, R. Synchronized trajectory tracking control of 3-DoF hydraulic translational parallel manipulator. In: Mechatronics - ideas for industrial application. Advances in Intelligent Systems and Computing [online]. Vol. 317. Cham: Springer, 2015. Available from: https://doi.org/10.1007/978-3-319-10990-9_24 